\title{
Morphology and dynamics of daytime mid- latitude sporadic-E patches revealed by GPS total electron content observations in Japan

Jun Maeda ${ }^{1,2}$ and Kosuke Heki ${ }^{1 *}$

\begin{abstract}
Morphological characteristics of daytime mid-latitude sporadic-E (Es) patches are studied by two-dimensional total electron content (TEC) maps drawn using the Japanese dense network of Global Positioning System (GPS) receivers. By analyzing over 70 cases, we found that their horizontal shapes are characterized by frontal structure typically elongated in east-west by $\sim 100 \mathrm{~km}$. They are observed to migrate mainly northward in the morning and southward in the afternoon with speeds of 30-100 m/s. This may reflect the velocities of neutral winds controlled by the atmospheric tides. Such frontal structures are often found to include smaller scale structures.
\end{abstract}

Keywords: Sporadic-E; lonosphere; GPS-TEC; Morphology; Wind shear; Atmospheric tide

\section{Findings}

Introduction

Sporadic-E (Es) is a thin densely ionized plasma patch, and its occurrence is highly unpredictable. It often appears in the E region of the ionosphere most frequently during the local summer in mid-latitude regions (Whitehead 1989, and references therein). Microwave signals from global navigation satellite system (GNSS), such as Global Positioning System (GPS), satellites penetrate the ionosphere, and Es sometimes degrades their positioning performance by exerting anomalous ionospheric delays. Es also causes unusual long-distance propagation of very high frequency (VHF) waves.

Since its discovery, the structure of Es has drawn the attention of investigators. Its two-dimensional (2-D) horizontal shape, however, has long remained ambiguous due to the lack of appropriate observation instruments. GPS radio occultation (GPS-RO) has revealed the spatial distribution of Es patches at a global scale (Wu et al. 2005; Arras et al. 2008), but its horizontal spatial resolution was not high enough to image individual patches.

With ground-based radar observations, 2-D horizontal shapes of nighttime Es have been imaged (Hysell et al.

\footnotetext{
* Correspondence: heki@mail.sci.hokudai.ac.jp

'Department of Natural History Sciences, Hokkaido University, N10 W8,

Kita-ku, Sapporo, Hokkaido 060-0810, Japan

Full list of author information is available at the end of the article
}

2002, 2004; Larsen et al. 2007). For example, Hysell et al. (2009) used a coherent scatter radar (CSR) at St. Croix, US Virgin Islands, the Caribbean Sea, to observe Es. They revealed horizontal structures of field-aligned irregularities (FAIs) possibly embedded in Es. These structures are elongated in E-W and/or NW-SE and drift perpendicular to the elongation azimuth. In recent years, Kurihara et al. (2010) have revealed the 2-D image of an Es patch by the magnesium ion imager on board a rocket flying over southwestern Japan. The patch had a horizontal dimension of $30 \times 10 \mathrm{~km}$ and showed elongation in NW-SE. Recently, Maeda and Heki (2014) succeeded in the 2-D imaging of daytime mid-latitude Es with total electron content (TEC) observations from a dense network of GPS receivers in Japan. They showed several images of clear frontal structures extending in EW over $100 \mathrm{~km}$.

Numerical simulations suggested that Es patches are preferably aligned in NW-SE and propagate southwestward in the Northern Hemisphere (Cosgrove and Tsunoda 2002, 2004; Yokoyama et al. 2009). However, there have not been a sufficient enough number of observations of the horizontal structures, temporal evolution, and drifts of Es to substantiate such simulation results.

Widely accepted generation mechanisms of Es under the presence of vertical shear of zonal winds include atmospheric gravity waves (Woodman et al. 1991; Didebulidze 
and Lomidze 2010; Chu et al. 2011; Liu et al. 2014), shear instability (Larsen 2000; Bernhardt 2002; Larsen et al. 2007; Hysell et al. 2009), and the Es-layer instability (Cosgrove and Tsunoda 2002, 2004). At the moment, it is difficult to tell which mechanism is dominant because of the scarcity of observed cases. Hence, studies of morphology and dynamics of Es, e.g., horizontal shapes and movements, are indispensable to discuss their generation mechanisms. There have been no observations of FAIs in daytime Es with ground-based radars. Thus, their observations are especially valuable. In this paper, we discuss large-scale structures (horizontal scales of tens to several hundreds of kilometers) of daytime mid-latitude Es patches. Over $~ 70$ Es events during 2010, with a few additional events in 2011 and 2013, are analyzed based on GPS-TEC observations to characterize their morphology and dynamics.

\section{GNSS data analyses}

The electron density in intensely ionized Es patches, e.g., those with critical frequency of the Es layer (foEs) over
$16 \mathrm{MHz}$, can exceed the peak density in the $\mathrm{F}$ region of the ionosphere. It causes extra ionospheric delays of microwaves and can be detected with TEC observations with dual-frequency GNSS receivers (Maeda and Heki 2014). In this study, we analyzed the data from the GNSS Earth Observation Network (GEONET), composed of $\sim 1200$ continuously operating receivers in Japan. GEONET is operated by the Geospatial Information Authority of Japan, and the raw data are available online for registered users (terras.gsi.go.jp). Spatial resolution of a TEC map is $15-25 \mathrm{~km}$ as a result of horizontal separations of GNSS stations (Fig. 1). The time resolution is $30 \mathrm{~s}$.

In this study, we used only GPS (the American GNSS) data because most GEONET receivers tracked only GPS satellites in 2010. GPS satellites transmit two microwave carriers, i.e., $\sim 1.5 \mathrm{GHz}$ (L1) and $\sim 1.2 \mathrm{GHz}$ (L2). We calculated the phase differences between L1 and L2 expressed in length, with which we can monitor changes of TEC along the line of sight (LOS); this is called slant

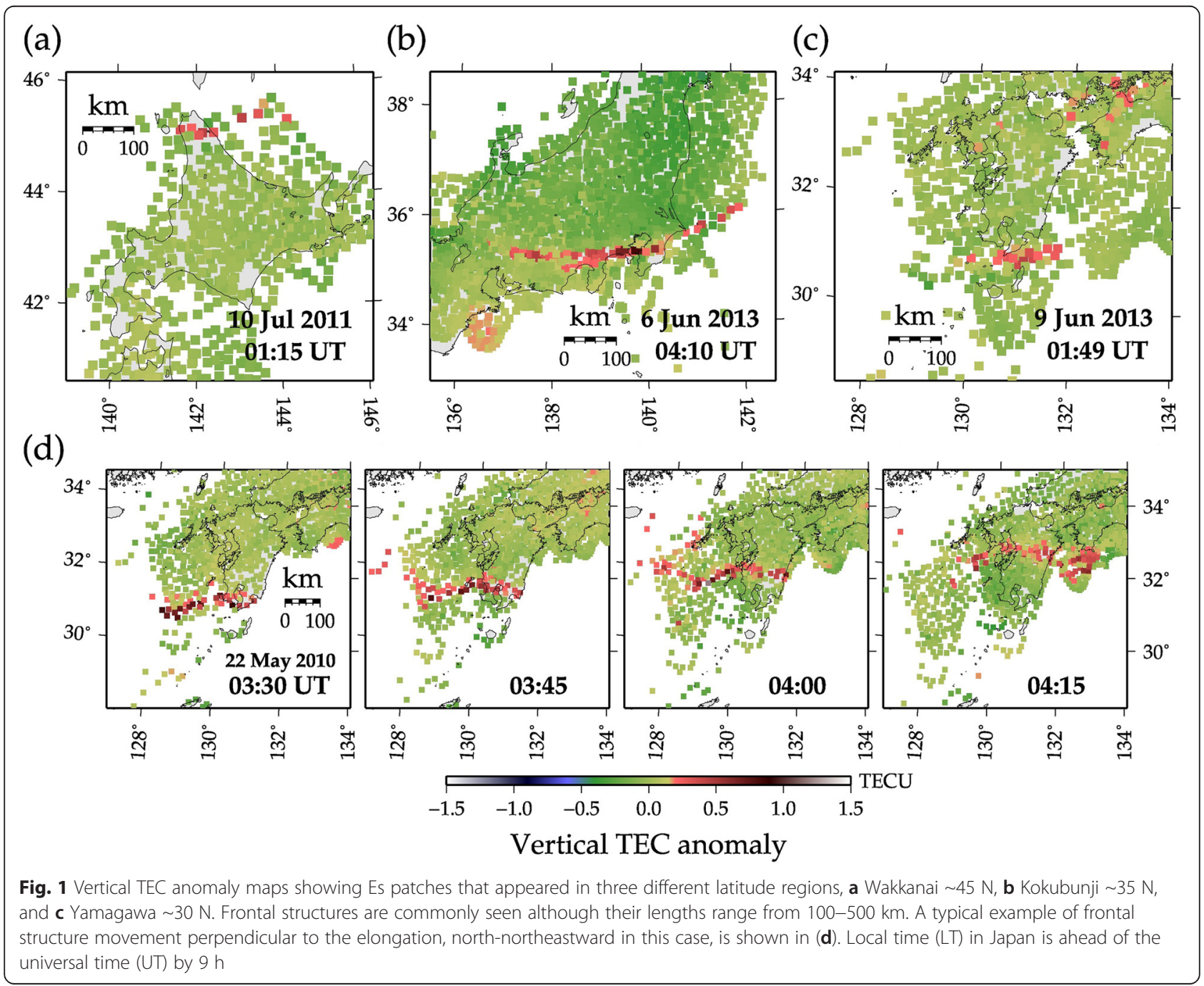


TEC (STEC). In STEC time series, Es patches are recognized as short positive pulses (Maeda and Heki 2014). They are clearly recognizable during daytime (Fig. 2a). During nighttime, however, medium-scale traveling ionospheric disturbances (MSTIDs) frequently occur and often make it difficult to identify such Es signatures. We therefore treat only daytime Es in this study.

We modeled the long-period changes of STEC assuming that the vertical TEC (VTEC) obeys a cubic polynomial of time and estimated their coefficients together with phase ambiguities following the method of Ozeki and Heki (2010). The residuals are converted to VTEC (we call them VTEC anomalies) by multiplying with the cosine of the incident angle of LOS with a thin layer at the ionospheric E-region altitude $(100 \mathrm{~km})$. The coordinates of the ionospheric pierce points (IPPs) were also calculated assuming a thin layer as high as $100 \mathrm{~km}$. To image horizontal structures of Es, we plotted the VTEC anomalies on their sub-ionospheric points (SIPs), ground projections of IPPs (Fig. 1).

Altitudes of anomalies are confirmed to be in the E region of the ionosphere by matching the images of Es patches drawn with multiple satellites (see Fig. 3 in Maeda and Heki 2014). After these processes, we studied morphological characteristics of horizontal structures, i.e., length, width, elongation azimuth, and their migration velocities, read by eye using 5 min snapshots like those shown in Fig. 3. We consider that they include reading errors approximately $25 \mathrm{~km}$ and $10^{\circ}$ for length and azimuth of the Es patches, respectively.

\section{Observation results}

\section{2-D horizontal structures}

Figure 1a-c shows VTEC anomaly maps with Es patches in three areas of different geographic latitudes, namely (a) Wakkanai, $\sim 45 \mathrm{~N}$, (b) Kokubunji, $\sim 35 \mathrm{~N}$, and (c) Yamagawa, $\sim 30 \mathrm{~N}$. There the National Institute of Information and Communications Technology has been operating ionosondes for decades. We first searched intense Es (foEs $>16 \mathrm{MHz}$ ) in their foEs data sets in order to make up a list of events to be studied with the GPS-TEC method.

In each panel of Fig. 1, three satellites or more are used to realize extensive and dense spatial coverage of SIP. Red dots represent positive VTEC anomalies and possibly show 2-D horizontal structures of Es patches. Figure 1a-c suggests that the frontal structure is commonly seen for intensely ionized daytime Es patches in this latitude range. The Es patch in Fig. 1b is elongated in $\mathrm{E}-\mathrm{W}$ by $\sim 500 \mathrm{~km}$ with a gentle curvature. The other two cases (Fig. 1a, c) show lengths of 150-200 km. Their N-S widths are in the range of $10-30 \mathrm{~km}$. Maeda and Heki (2014) estimated the thickness of the layer with peak electron density by comparing the amplitudes of the VTEC anomaly and foEs. In the cases shown in Fig. 1, they are $\sim 1 \mathrm{~km}$ (Fig. 1a-c) and $\sim 2 \mathrm{~km}$ (Fig. 1d).

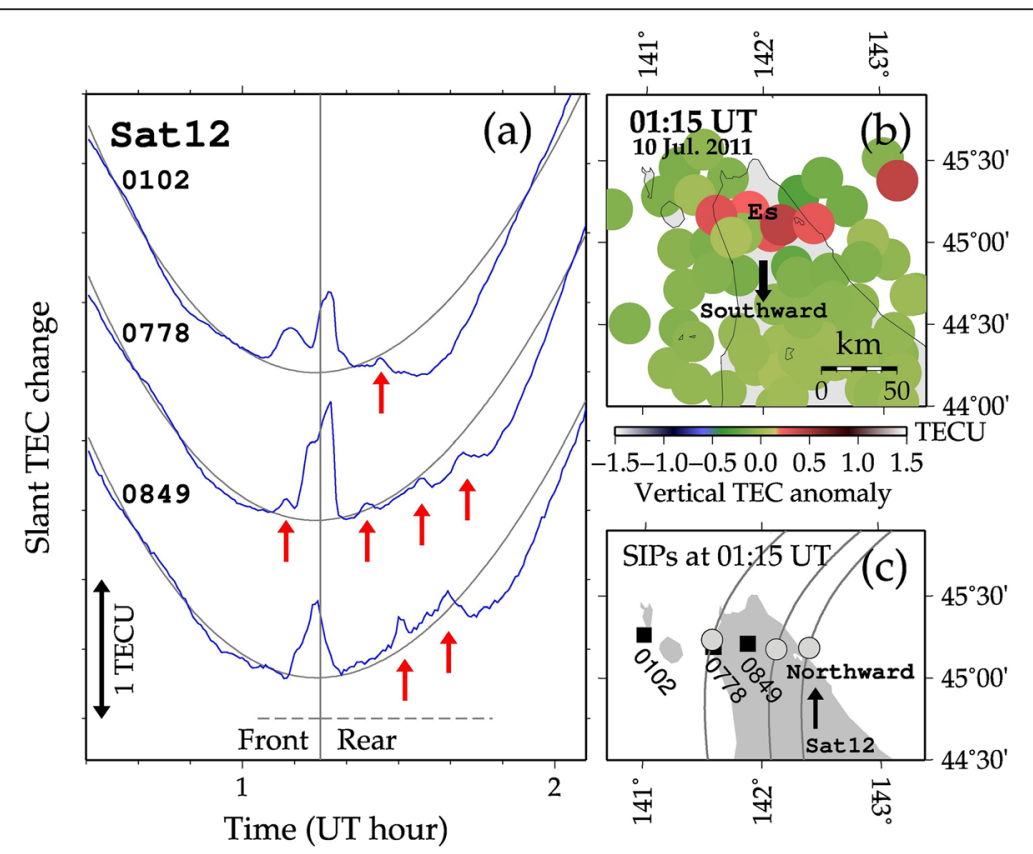

Fig. 2 a STEC time series showing dominant TEC anomalies accompanied by several small positive peaks (indicated by red arrows). Because this Es patch was moving southward, the period earlier than 01:15 UT represents the front side of the structure. $\mathbf{b}$ VTEC anomaly map at 01:15 UT, showing a patchy frontal structure elongated in E-W. c SIP positions with satellite 12 and the three GPS stations at 01:15 UT. Satellite 12 moved northward across the Es in the time window of a 

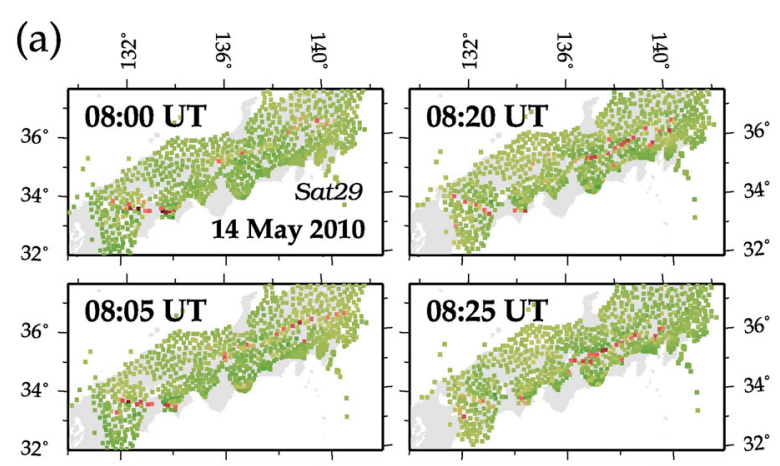

(b)
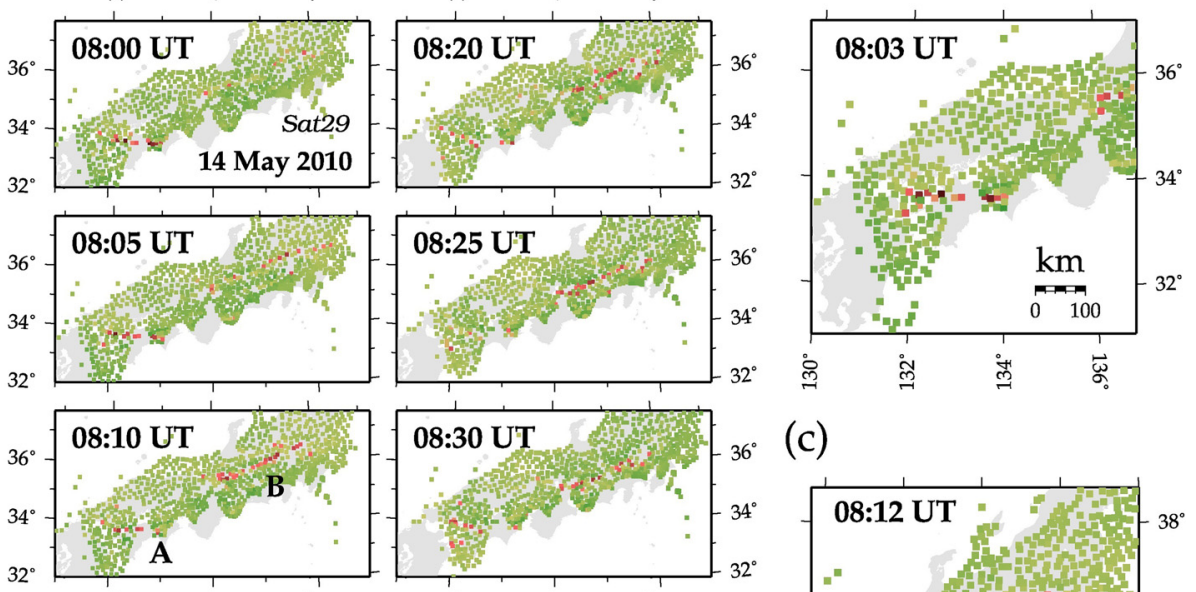

(c)
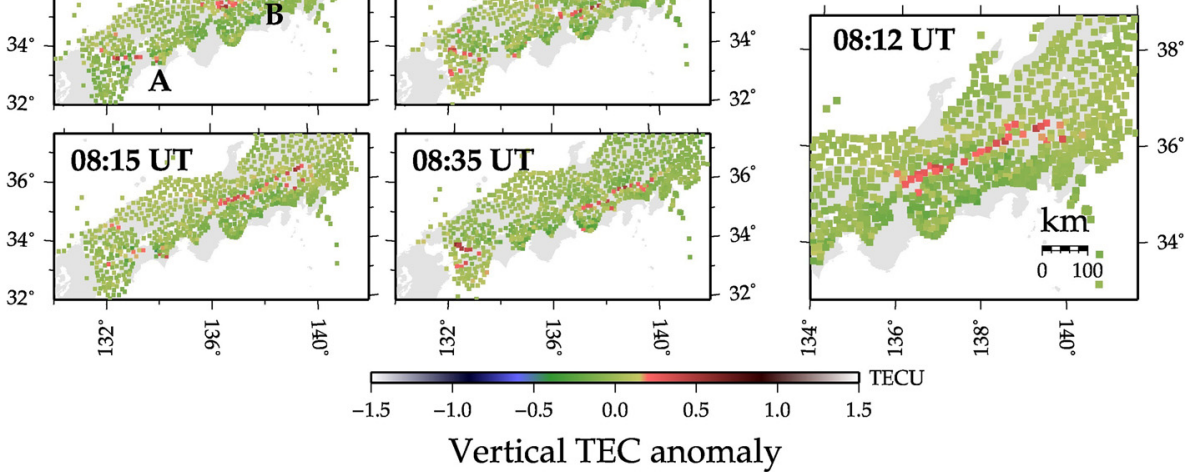

Fig. 3 a 5 min snapshots of vertical TEC anomaly map in the period 08:00-08:35 UT ( $L T=U T+9)$. Simultaneous occurrence of two frontal structures can be seen over the southwestern and central part of Japan, which are labeled as $A$ and $B$ in the snapshot at 08:10 UT, respectively. The enlarged images of the structures $A$ and $B$ at their maximum lengths are shown in $\mathbf{b}$ and $\mathbf{c}$, respectively

\section{Small-scale sub-structure}

Smaller scale structures with horizontal-scale size of a few kilometers are also found by examining raw STEC time series. We here examine the case shown in Fig. 1a (northern Japan). Figure 2a shows STEC time series obtained by satellite 12 and three GPS stations. There we can see a large positive anomaly around 01:15 universal time (UT) (vertical gray line) at each GPS station. At this moment, a clear E-W elongated frontal structure was drifting southward (Fig. 2b) while IPP of satellite 12 was moving northward (Fig. 2c). Hence, the STEC changes in Fig. 2a show the structure in the N-S cross section of the frontal structure, and the changes before and after the peak at 01:15 UT reflect the structures at front and rear sides, respectively.

In addition to the main anomaly at 01:15 UT, quasiperiodic (QP) TEC enhancements can be seen as smaller positive peaks (red arrows). They are mainly seen at the rear side of the primary structure. The QP TEC signatures are clearer at stations 0778 and 0849 than at 0102 , suggesting further development of internal structure in the central and eastern part of the Es front. The horizontal size and spacing of small plasma patches within the frontal structure are $\sim 4 \mathrm{~km}$ and $20-25 \mathrm{~km}$, respectively.

\section{Migration and rapid change in shape}

Figure 1d shows snapshots at four time epochs and the movement of an Es patch with typical frontal structure. Although its eastern and western ends are out of the GEONET coverage, its northward migration can be seen. Such movements perpendicular to the elongation are often observed.

Figure 3a shows snapshots of a VTEC anomaly map taken every 5 min during 08:00-08:35 UT. Two separate frontal structures, labeled as A and B in the third snapshot, are seen above the southwestern and central Japan, respectively. Their elongation directions at 08:10 UT are different, i.e., the structure A extends in $\mathrm{E}-\mathrm{W}$ while the structure B extends in NE-SW. Structure A is the longest $(\sim 200 \mathrm{~km})$ at 08:03 UT (Fig. 3b) while structure B is the longest $(\sim 400 \mathrm{~km})$ at 08:12 UT (Fig. 3c).

The two structures show rather rapid changes in shape. During 08:00-08:10 UT, they behave in a seesaw manner, i.e., structure A becomes obscure while structure B becomes clearer and vice versa. Structure A repeats cycles of appearance and decay, e.g., it is clear at 08:00-08:10 UT but becomes obscure 5 min later (08:15 UT). The elongation azimuth of structure A changed from E-W to NWSE around 08:20 UT and then to WNW-ESE during 08:30-08:35 UT. After 08:35 UT, it became obscure. 
Structure B was more stable during 08:05-08:25 UT. Its elongation azimuth remained ENE-WSW, and its length hardly changed. After 08:30 UT, however, structure B dissolved into small patches. At 08:35 UT, it split into two small frontal structures (boundary $~ 138 \mathrm{E}$ ) running parallel with each other.

\section{Statistical characteristics}

Figure 4 shows the distributions of (a) elongation azimuth, (b) length, and (c) speed of elongation-normal migration of 71 Es patches with frontal structures found in 2010. The rose diagram (Fig. 4a) shows a preferred elongation in E-W. The histogram (Fig. 4b) shows that the lengths of the frontal structures range from 50 to $500 \mathrm{~km}$ with the average of $\sim 160 \mathrm{~km}$. The median is $\sim 100 \mathrm{~km}$, and smaller distribution peaks exist at $\sim 250$ and $\sim 450 \mathrm{~km}$.

Figure $4 \mathrm{c}$ shows the migration speed normal to the elongation azimuths. There we neglected the movements in the elongation direction because they cannot be clearly distinguished from the temporal growth of Es patches in the elongation direction. Because the structures are elongated preferably in E-W, their migration directions are either northward or southward. Figure 4c suggests that the speeds range from 30 to $100 \mathrm{~m} / \mathrm{s}$ with the average of $\sim 60 \mathrm{~m} / \mathrm{s}$ for both directions.

\section{Preferred time of occurrences and migration directions}

Figure 5 shows local time dependence of the number of Es frontal structures observed in 2010 and their elongation-normal movements (classified simply as northward or southward). Numbers of northward- and southwardmoving Es patches are shown by orange and gray colors, respectively. Here, we exclude Es observed in the northern and southern Japan, and discuss 24 cases observed over the central part of Japan where a larger latitudinal coverage of densely distributed GNSS stations allows detailed analyses of the migration of Es patches (Fig. 1b). There we also show the hourly occurrence rates of strong Es (foEs $>10 \mathrm{MHz}$ ) observed by the Kokubunji ionosonde during 2010 and during 2003-2012. The Kokubunji ionosonde $(35.71 \mathrm{~N}, 139.49 \mathrm{E})$ is also in the central part of Japan.

The histogram in Fig. 5 suggests that Es patches move mainly northward in 10-14 local time (LT) and mainly southward in 17-19 LT. The Es occurrence rates from

\section{(a) Azimuthal alignment}

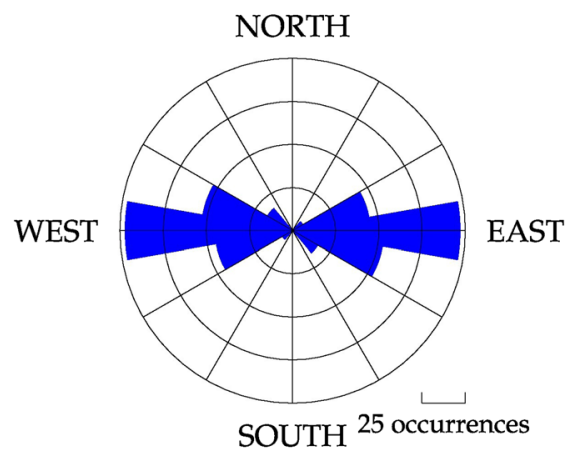

\section{(b) Length}

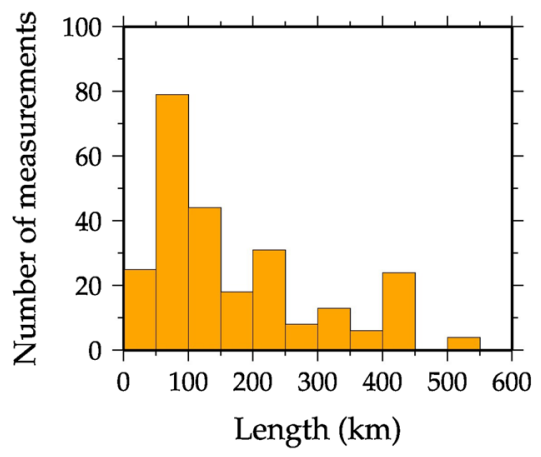

(c) Meridional speed

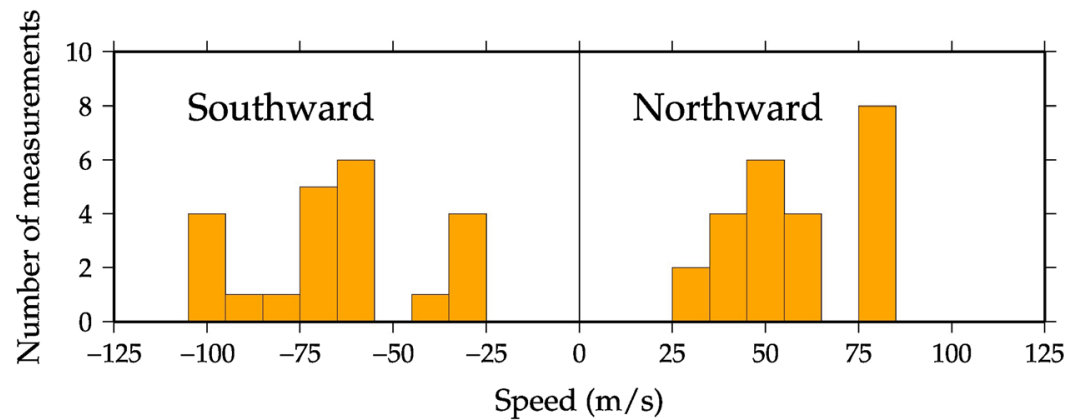

Fig. 4 Histograms showing the distributions of $\mathbf{a}$ elongation azimuth, $\mathbf{b}$ length, and $\mathbf{c}$ migration speed of Es patches with frontal structures observed in 2010. They are typically elongated in E-W with the median length of $\sim 100 \mathrm{~km} \mathbf{b}$. In c, N-S components of the migration velocities are shown. They are distributed in the range of $30-100 \mathrm{~m} / \mathrm{s}$ with the average of $60 \mathrm{~m} / \mathrm{s}$ 


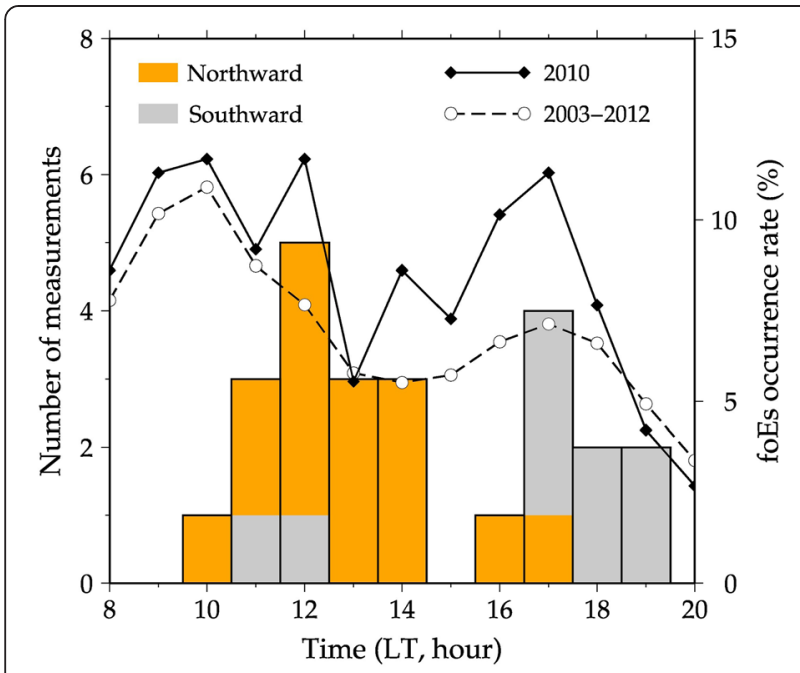

Fig. 5 Local time dependence of the directions of $\mathrm{N}-\mathrm{S}$ drifts of $\mathrm{ES}$ patches observed in 2010 (histogram). We only show observations made in central Japan where GPS-TEC data have a better spatial coverage and resolution. In the histogram, orange and gray represent the numbers of northward and southward drifting Es patches, respectively. Curves show occurrence rates of Es from foEs data during 2003-2012 (dashed) and 2010 (solid) by the Kokubunji ionosonde (we show only the cases with foEs > $10 \mathrm{MHz}$ )

the ionosonde during 2003-2012 show maxima around 10 and 17 LT and a minimum of 13-15 LT. The peak in northward moving Es from GPS-TEC lags behind the morning peak of the Es occurrence rate from the ionosonde by $\sim 2 \mathrm{~h}$. The same is true for the minimum occurrence hour in the afternoon. The peak of southward movement from GPS-TEC coincides with that of the occurrence rate from the ionosonde. The distribution of the occurrence hour from the ionosonde during 2010, the same period as the GPS-TEC study, shows morning peaks at 10 and 12 LT followed by a drop of 13-15 LT and the evening peak at 17 LT. The peaks of northward and southward drifts coincide with those of the morning and evening peaks of the Es occurrence hours in 2010.

\section{Discussion}

\section{Horizontal shapes and dynamics of Es patches}

By mapping VTEC anomalies from a dense network of continuous GNSS receivers, we found that Es patches have frontal structures elongated in E-W over the entire latitude range studied here (Fig. $1 \mathrm{a}-\mathrm{c}$ ). In fact, no frontal structures elongated in N-S have been observed (Fig. 4a).

As already described in the 'Introduction' section, 2-D horizontal images of nighttime Es patches have been studied by CSR and rocket experiments, and Larsen et al. (2007) showed 30-100 km-scale banded structures aligned typically in E-W and/or NW-SE. They also analyzed the motions of these Es patches by consecutive radar images and found dominant north- and southward movements. Their observations are consistent with our results on the large-scale structure (Fig. 4c).

The mechanisms responsible for such structures are not clear, but zonal winds may be related to the elongation azimuths. Es layers in mid-latitude regions are considered to be formed under vertical wind shear (Whitehead 1989). Vertical shear of zonal winds drives upward and downward ion motions from layers below and above the Es height, respectively (Larsen et al. 1998; Larsen 2002; Haldoupis 2012). The E-W elongation of frontal structures may reflect the shape of the region where vertical shear of zonal winds exist.

\section{Small-scale structures}

Frontal structures are inhabited by several kinds of smaller scale irregularities, e.g., plasma blobs with meter to kilometer scales (Maruyama et al. 2000; Hysell et al. 2013). In Fig. 2, we showed that such small-scale plasma blobs do exist within a frontal structure. Kurihara et al. (2010) showed that the frontal shape of plasma blobs aligned in NW-SE with a horizontal scale of $30 \times 10 \mathrm{~km}$. Three-dimensional structures of QP echoes associated with mid-latitude Es are observed by MU radar (Saito et al. 2006). The sizes of the frontal structures shown by these studies correspond to only a few colored circles in our TEC maps. Hence, large-scale frontal structures presented in this study may consist of tiny blobs that also have small-scale frontal structures.

Such small-scale (kilometer-scale or less) structures are often observed as QP echoes in the backscatter radar observations (Yamamoto et al. 1991, 1992, 1994). QP scintillations found in the VHF radio wave signals from a geostationary satellite have been attributed to the electron density gradient in small-scale Es blobs (Maruyama 1991). Their waveforms are morphologically in good agreement with the QP echoes (Maruyama et al. 2000). Figure 2a suggests that TEC changes more quickly in the rear side of the structure (e.g., 0778), and this is consistent with the QP scintillation events reported by Maruyama (1991, 1995).

The horizontal scale of small plasma blobs as seen in the daytime case shown in Fig. 2 is $\sim 4 \mathrm{~km}$, and they are separated in N-S by $20-25 \mathrm{~km}$. These properties are similar to those reported by nighttime backscatter radar observations in QP echo events (Tsunoda et al. 2000; Hysell et al. 2004; Saito et al. 2005). Local time dependence of the morphological properties of such QP signatures would be an important future issue to be studied with more daytime Es observations.

Numerical simulations predict southwestward propagation of Es patches aligned in NW-SE (Cosgrove and Tsunoda 2002, 2004; Yokoyama et al. 2009) during nighttime, while Es patches observed in this study during daytime showed preferred elongation in E-W. Es-layer 
instability may not work during daytime because polarization electric fields generated by the instability could be shorted out under the presence of relatively high density of the ambient E-region plasma. Thus, it seems natural that the daytime Es shows different directional preference in its horizontal elongation. Other instabilities, e.g., Kelvin-Helmholtz instability, which has no directional preference, may play a key role in the formation of smallscale QP structures observed in the present study.

Larsen et al. (2007) reported complex propagation of multiple small-scale structures within a banded structure, e.g., one structure moved toward N-NW while another structure moved eastward simultaneously. The spatial resolution of our TEC anomaly maps (15-25 km) is not high enough to image such small-scale plasma blobs. Enhanced spatial resolution should be pursued in the future taking advantage of increasing the number of GNSS other than GPS.

\section{Diversity in dynamics}

Simultaneous occurrence and different temporal evolution of the two frontal-structure Es patches as shown in Fig. 3 revealed diversity of the time evolution of complicated Es structures. There structure A is shorter in length and lifetime and changed its shape more rapidly than structure B. The two structures would have been created by two different wind shear systems, and the wind shear around structure A may have been more unstable. Their horizontal dimensions would reflect those of the wind shear.

The GPS-TEC technique can also provide a better understanding of ionosonde data. Records by multiple ionosondes in Japan separated by more than $1000 \mathrm{~km}$ often show simultaneous occurrences of Es (enhancement of foEs). It is not clear whether they represent the appearance of a single large Es structure or just a simultaneous appearance of multiple Es structures (From and Whitehead 1986). Comparison of ionosonde records and 2-D TEC maps would enable us to answer these questions in the future.

\section{Es migration and atmospheric tides}

In Fig. 5, northward movements dominate from late morning to early afternoon, and southward movements dominate from late afternoon to evening. The reversal from southward to northward seems to occur during the night, but the detail is not clear due to the lack of nighttime Es observations. Tanaka (1979) investigated local time dependence of the movements of Es patches by radar backscatter observations. He showed that northward and southward movements are dominant during 12-14 LT and 16-21 LT, respectively. This agrees with our observations.
Between the periods of northward and southward movements, there is a silent period at $\sim 15$ LT. This period would represent the direction transition of meridional wind from northward to southward. In fact, Tanaka (1979) found that the Es drift vectors slowly rotate counterclockwise in time, i.e., from northward to westward and then to southward. The westward drift peaks at around $15 \mathrm{LT}$, which roughly coincides with the silent period in Fig. 5 (please remember that we neglect elongation-parallel movements here).

The northward Es migration in the local morning is consistent with the E-region horizontal wind vectors at mid-latitudes inferred from diurnal (Sq) geomagnetic variation (Kato 1956). Such north- and southward Es movements might be driven by semidiurnal tide (Maeda 1957; Elford 1959), although the tidal winds are generally slower than the Es migration speeds observed in our study. The whole wind system, including the vertical wind shear responsible for Es generation, might move together with the global-scale atmospheric tidal winds. Arras et al. (2009) also showed semidiurnal tidal signature on the variability of Es occurrences from GPS-RO data.

The foEs data over a 10-year period in Fig. 5 suggest 8 $\mathrm{h}$ periodicities in the Es occurrences. According to Haldoupis and Pancheva (2006), foEs data show peaks at 6- and 8-h periods in the Es occurrence. They found the 8-h periodicity more regular and significant and attributed it to atmospheric tides. Both the reversal of Es migration directions and 8-h Es occurrence periodicity in Fig. 5 suggest that atmospheric tidal winds may govern the occurrence and drifts of Es patches.

\section{Role of gravity waves}

In addition to atmospheric tides, we should consider internal gravity waves in discussing the evening southward movement of Es patches. Liu et al. (2014) suggested that strong winds and wind shears are produced by the nonlinear interactions between gravity waves and tidal backgrounds. Maeda and Heki (2014) reported the fragmentation of frontal structure associated with MSTID passage, i.e., E-W-elongated Es patches dissolved into smaller wave-like pieces aligned in NW-SE. The horizontal separation of the pieces is $\sim 40 \mathrm{~km}$, and they moved southwestward by $\sim 80 \mathrm{~m} / \mathrm{s}$ in the local evening. These observations indicate possible interaction of gravity waves in the destruction of large-scale frontal structure and following southward migration of small Es pieces.

As shown in Fig. 4c, speeds of Es frontal structure movements are similar to those of neutral winds and gravity waves observed in the $\mathrm{E}$ region (somewhat faster than those driven by semidiurnal tides). Further investigations of Es movements are needed to reveal the dynamics of the E-region neutral atmosphere. For that 
purpose, we would need simultaneous measurements of E-region winds by, e.g., rocket experiments, and Es movements by the GPS-TEC method, under the existence of strong Es. The refinement of our knowledge as shown in Fig. 5 would help us investigate the coupling between the neutral atmosphere and plasma movement in the ionospheric E region.

\section{Conclusions}

We have shown several morphological characteristics and dynamics of mid-latitude $(30 \mathrm{~N}-45 \mathrm{~N})$ Es patches by daytime GPS-TEC observations in Japan. This study can be summarized as follows:

(1). Intensely ionized daytime Es patches show frontal structures with typical elongation in E-W.

(2). Typical lengths and widths of Es frontal structures are $50-500 \mathrm{~km}$ and $10-30 \mathrm{~km}$, respectively.

(3). Small-scale sub-structures, characterized by QP TEC signature, are often found to accompany the main frontal structure.

(4). Northward and southward movements, perpendicular to the elongation azimuths, are observed. They are $30-100 \mathrm{~m} / \mathrm{s}$ with the average of $60 \mathrm{~m} / \mathrm{s}$ in both directions.

(5). Tidal winds in the neutral atmosphere may control the migration direction of Es frontal structures.

\section{Competing interests}

The authors declare that they have no competing interests.

\section{Authors' contributions}

JM conducted the analyses and wrote the manuscript. KH proposed the initial idea and discussed the results. Both authors read and approved the final manuscript.

\section{Acknowledgements}

We thank Geospatial Information Authority of Japan for the GEONET GPS data and the National Institute of Information and Communications Technology for ionosonde data. We thank Shigeto Watanabe and Jun'ichi Kurihara for discussions. Constructive comments by a reviewer and the editor improved the manuscript.

\section{Author details}

'Department of Natural History Sciences, Hokkaido University, N10 W8, Kita-ku, Sapporo, Hokkaido 060-0810, Japan. ${ }^{2}$ Hokkaido University Library, N8 W5, Kita-ku, Sapporo, Hokkaido 060-0808, Japan.

Received: 27 December 2014 Accepted: 27 May 2015

Published online: 11 June 2015

\section{References}

Arras C, Wickert J, Beyerle G, Heise S, Schmidt T, Jacobi C (2008) A global climatology of ionospheric irregularities derived from GPS radio occultation. Geophys Res Lett 35:L14809. doi:10.1029/2008GL034158

Arras C, Jacobi C, Wickert J (2009) Semidiurnal tidal signature in sporadic E occurrence rates derived from GPS radio occultation measurements at higher midlatitudes. Ann Geophys 27:2555-2563. doi:10.5194/angeo-27-2555-2009

Bernhardt PA (2002) The modulation of sporadic-E layers by Kelvin-Helmholtz billows in the neutral atmosphere. J Atmos Solar-Terr Phys 64:1487-1504

Chu Y-H, Brahmanandam PS, Wang C-Y, Ching-Lun S, Kuong R-M (2011) Coordinated sporadic E layer observations made with Chung-Li $30 \mathrm{MHz}$ radar, ionosonde and FORMOSAT-3/COSMIC satellites. J Atmos Solar-Terr Phys 73:883-894
Cosgrove RB, Tsunoda RT (2002) A direction-dependent instability of sporadic- $E$ layers in the nighttime midlatitude ionosphere. Geophys Res Lett 29:1864. doi:10.1029/2002GL014669

Cosgrove RB, Tsunoda RT (2004) Instability of the E-F coupled nighttime midlatitude ionosphere. J Geophys Res 109:A04305. doi:10.1029/ 2003JA010243

Didebulidze GG, Lomidze LN (2010) Double atmospheric gravity wave frequency oscillations of sporadic E formed in a horizontal shear flow. Phys Lett A 374:952-959

Elford WG (1959) A study of winds between 80 and $100 \mathrm{~km}$ in medium latitudes. Planet Space Sci 1:94-101

From WR, Whitehead JD (1986) $E_{s}$ structure using an HF radar. Radio Sci 21:309-312. doi:10.1029/RS021i003p00309

Haldoupis C (2012) Midlatitude sporadic E layers. A typical paradigm of atmosphere-ionosphere coupling. Space Sci Rev 168:441-461

Haldoupis C, Pancheva D (2006) Terdiurnal tidelike variability in sporadic E layers. J Geophys Res 111:A07303. doi:10.1029/2005JA011522

Hysell DL, Yamamoto M, Fukao S (2002) Imaging radar observations and theory of type I and type II quasi-periodic echoes. J Geophys Res 107:1360. doi:10.1029/2002JA009292

Hysell DL, Larsen MF, Zhou QH (2004) Common volume coherent and incoherent scatter radar observations of mid-latitude sporadic E-layers and QP echoes. Ann Geophys 22:3277-3290. doi:10.5194/angeo-22-32772004

Hysell DL, Nossa E, Larsen MF, Munro J, Sulzer MP, González SA (2009) Sporadic E layer observations over Arecibo using coherent and incoherent scatter radar: assessing dynamic stability in the lower thermosphere. J Geophys Res 114:A12303. doi:10.1029/2009JA014403

Hysell DL, Nossa E, Aveiro HC, Larsen MF, Munro J, Sulzer MP, González SA (2013) Fine structure in midlatitude sporadic E layers. J Atm Solar-Terr Phys 103:16-23. doi:10.1016/j.jastp.2012.12.005

Kato S (1956) Horizontal wind systems in the ionospheric E region deduced from the dynamo theory of the geomagnetic Sq Variation Part II. J Geomag Geoelectr 8:24-37

Kurihara J, Koizumi-Kurihara Y, Iwagami N, Suzuki T, Kumamoto A, Ono T, Nakamura M, Ishii M, Matsuoka A, Ishisaka K, Abe T, Nozawa S (2010) Horizontal structure of sporadic $E$ layer observed with a rocket-borne magnesium ion imager. J Geophys Res 115:A12318. doi:10.1029/2009JA014926

Larsen MF (2000) A shear instability seeding mechanism for quasiperiodic radar echoes. J Geophys Res 105:24931-24940. doi:10.1029/1999JA000290

Larsen MF (2002) Winds and shears in the mesosphere and lower thermosphere: results from four decades of chemical release wind measurements. J Geophys Res Space Phys 107. doi:10.1029/2001JA000218

Larsen MF, Fukao S, Yamamoto M, Tsunoda R, Igarashi K, Ono T (1998) The SEEK chemical release experiment: observed neutral wind profile in a region of sporadic-E. Geophys Res Lett 25:1789-1792

Larsen MF, Hysell DL, Zhou QH, Smith SM, Friedman J, Bishop RL (2007) Imaging coherent scatter radar, incoherent scatter radar, and optical observations of quasiperiodic structures associated with sporadic E layers. J Geophys Res 112:A06321. doi:10.1029/2006JA012051

Liu X, Xu J, Yue J, Liu HL, Yuan W (2014) Large winds and wind shears caused by the nonlinear interactions between gravity waves and tidal backgrounds in the mesosphere and lower thermosphere. J Geophys Res Space Phys 119:7698-7708. doi:10.1002/2014JA020221

Maeda H (1957) Horizontal wind systems in the ionospheric E region deduced from the dynamo theory of the geomagnetic Sq variation part III. J Geomag Geoelectr 9:86-93

Maeda J, Heki K (2014) Two-dimensional observations of midlatitude sporadic E irregularities with a dense GPS array in Japan. Radio Sci 49:28-35. doi:10.1002/2013RS005295

Maruyama T (1991) Observations of quasi-periodic scintillations and their possible relation to the dynamics of $E_{s}$ plasma blobs. Radio Sci 26:691-700. doi:10.1029/91RS00357

Maruyama T (1995) Shapes of irregularities in the sporadic E layer producing quasi-periodic scintillations. Radio Sci 30(3):581-590. doi:10.1029/95RS00830

Maruyama T, Fukao S, Yamamoto M (2000) A possible mechanism for echo striation generation of radar backscatter from midlatitude sporadic E. Radio Sci 35:1155-1164. doi:10.1029/1999RS002296

Ozeki M, Heki K (2010) lonospheric holes made by ballistic missiles from North Korea detected with a Japanese dense GPS array. J Geophys Res 115:A09314. doi:10.1029/2010JA015531 
Saito S, Yamamoto M, Fukao S, Marumoto M, Tsunoda RT (2005) Radar observations of field-aligned plasma irregularities in the SEEK-2 campaign Ann Geophys 23:2307-2318. doi:10.5194/angeo-23-2307-2005

Saito S, Yamamoto M, Hashiguchi H, Maegawa A (2006) Observation of threedimensional structures of quasi-periodic echoes associated with mid-latitude sporadic-E layers by MU radar ultra-multi-channel system. Geophys Res Lett 33:L14109. doi:10.1029/2005GL025526

Tanaka T (1979) Sky-wave backscatter observations of sporadic-E over Japan J Atmos Terr Phys 41:203-215

Tsunoda RT, Yamamoto M, Mori H, Fukao S (2000) SEEK S310-25: quasi-periodic echoes and polarization electric fields. Geophys Res Lett 27:3281

Whitehead JD (1989) Recent work on mid-latitude and equatorial sporadic $E$. J Atmos Terr Phys 51:401-424

Woodman RF, Yamamoto M, Fukao S (1991) Gravity wave modulation of gradient drift instabilities in mid-latitude sporadic $E$ irregularities. Geophys Res Lett 18:1197-1200. doi:10.1029/91GL01159

Wu DL, Ao CO, Haij GA, de la Torre Juarez M, Mannucci AJ (2005) Sporadic E morphology from GPS-CHAMP radio occultation. J Geophys Res 110:A01306. doi:10.1029/2004JA010701

Yamamoto M, Fukao S, Woodman RF, Ogawa T, Tsuda T, Kato S (1991) Mid-latitude E region field-aligned irregularities observed with the MU radar. J Geophys Res 96:15943-15949. doi:10.1029/91JA01321

Yamamoto M, Fukao S, Ogawa T, Tsuda T, Kato S (1992) A morphological study of mid-latitude E-region field-aligned irregularities observed with the MU radar. J Atmos Terr Phys 54:769-777

Yamamoto M, Komoda N, Fukao S, Tsunoda RT, Ogawa T, Tsuda T (1994) Spatial structure of the $E$ region field-aligned irregularities revealed by the $\mathrm{MU}$ radar. Radio Sci 29:337-347. doi:10.1029/93RS01846

Yokoyama T, Hysell DL, Otsuka Y, Yamamoto M (2009) Three-dimensional simulation of the coupled Perkins and $E_{s}$-layer instabilities in the nighttime midlatitude ionosphere. J Geophys Res 114:A03308. doi:10.1029/2008JA013789

\section{Submit your manuscript to a SpringerOpen ${ }^{\circ}$} journal and benefit from:

- Convenient online submission

- Rigorous peer review

- Immediate publication on acceptance

- Open access: articles freely available online

- High visibility within the field

- Retaining the copyright to your article

Submit your next manuscript at $>$ springeropen.com 